\author{
Universidade de Brasília \\ Faculdade de Administração, Contabilidade e Economia \\ Departamento de Economia
}

\title{
Explicando o Fracasso na Tentativa de Reeleição dos Deputados Federais do Brasil
}

Mestrando: Henrique Tadeu de Pina Jayme

Orientadora: Prof. Dra. Andrea Felippe Cabello

\section{Brasília-DF}




\section{Agradecimentos}

Agradeço à minha família por todo o apoio dado para enfrentar mais esse desafio;

À Camomila, pelo incentivo;

À Professora Andrea Cabello, que tornou possível a conclusão deste Mestrado, pela compreensão e pelas orientações;

Aos demais professores da FACE, pelas aulas, seminários e inúmeros debates;

Aos meus colegas, que foram essenciais para o aprendizado da Economia, por todos os ensinamentos, por todas as discussões;

Aos pesquisadores do Ipea, em especial ao Bruno Amorim e ao André Gambier Campos, pelas orientações naquele instituto. 


\section{Resumo}

As eleições para os parlamentos brasileiros seguem o sistema proporcional por lista aberta para determinar os candidatos eleitos. Nesse sistema, cada coligação conquista um determinado número de cadeiras e os candidatos mais votados de cada coligação se elegem. O presente trabalho fará uma análise das eleições de 2014 para Deputado Federal no Brasil apresentando dados estatísticos com foco naqueles candidatos que pleitearam a reeleição. $O$ objetivo é cobrir uma lacuna existente na literatura: busca de variáveis que justifiquem o fracasso na reeleição para Deputado Federal. A hipótese levantada é de que os deputados que ficam mais desconcentrados eleitoralmente possuem mais dificuldade de se reelegerem. A avaliação será, principalmente, entorno daqueles candidatos que sofreram uma queda em sua votação de uma eleição para outra. Para os congressistas que deixaram de se candidatar algumas possibilidades são evidentes, como idade avançada, busca por outros cargos ou perda de apoio popular por casos de corrupção. Para os que perdem número de votos, deixando de se eleger, a análise é mais detalhada, buscando mudanças na concentração eleitoral do político. As hipóteses levantadas foram satisfeitas e novos estudos na área se mostraram necessários para complementar a literatura.

Palavras-Chave: Câmara Federal, Deputados, Reeleição, Concentração Eleitoral, Política, Eleições, Representação Proporcional. 


\section{Abstract}

The Elections for the Brazilian parliaments follow the Open List Proportional Representation system to determine the elected deputies. In this system, each winning coalition gains certain number of seats and the top candidates of each coalition are elected. This paper will make an analysis of the 2014 election for Federal Deputy in Brazil, presenting statistical data focusing on those candidates who tried the reelection. The goal is to cover a gap in the literature: search variables to justify the failure to re-election for Federal Deputy. The hypothesis is that Congressmen who are more decentralized electorally have more difficulty getting reelected. The evaluation will be mainly around those candidates who have suffered a drop in its vote from one election to another. For politicians who gave up running for reelection some possibilities are evident, such as advanced age, the search for other positions or loss of popular support because of corruption. For those who lose number of votes, failing to be elected, the analysis is more detailed, seeking changes in the electoral concentration of the Deputy. The hypotheses were met and new studies in the area have proved necessary to supplement the literature.

Keywords: Federal Chamber, Deputies, Reelection, Electoral Concentration, Politics, Elections, Congress, Proportional Representation. 


\section{Lista de Figuras}

Figura 1 - Alteração na concentração eleitoral dos candidatos à reeleição para a Câmara Federal

Figura 2 - Alteração na concentração eleitoral dos candidatos à reeleição do Sul, Sudeste e Centro-Oeste.

Figura 3 - Alteração na concentração eleitoral dos candidatos à reeleição do Norte e Nordeste. 


\section{Lista de Tabelas}

Tabela 1 - Status dos Deputados em 2014

Tabela 2 - Brasil - Índice G para eleitos em 2010 e em 2014 14

Tabela 3 - São Paulo - Índice G para eleitos em 2010 e em 2014 15

Tabela 4 - Estados com 8 cadeiras - Índice G para eleitos em 2010 e em 2014

Tabela 5 - Brasil - Índice G para os que tentaram a reeleição em 2014 16

Tabela 6 - Brasil - Análise dos novatos de 2010 na reeleição de 2014 17

Tabela 7 - Brasil - Concentração eleitoral de acordo com aumento/diminuição de votos

Tabela 8 - São Paulo - Concentração eleitoral de acordo com aumento/diminuição de votos

Tabela 9 - Estados com 8 cadeiras - Concentração eleitoral de acordo com aumento/diminuição de votos

Tabela 10 - Candidatos à Reeleição muito concentrados (acima de um desvio padrão da média)

Tabela 11 - Deputados Federais que buscaram outros postos 24 


\section{Sumário}

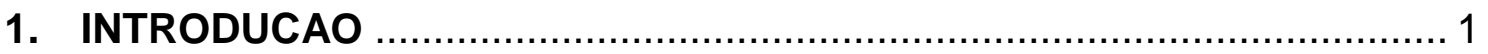

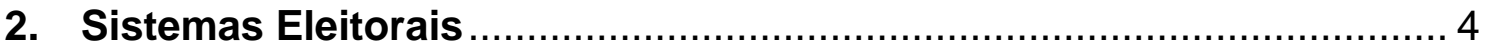

2.1. Sistema Eleitoral Brasileiro ...................................................... 5

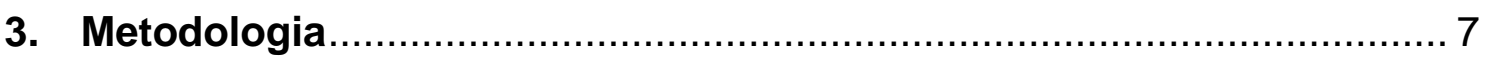

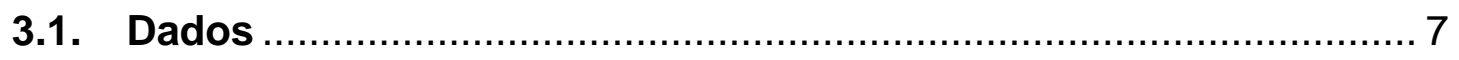

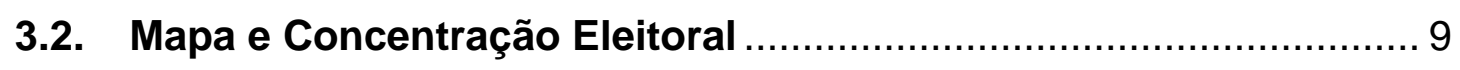

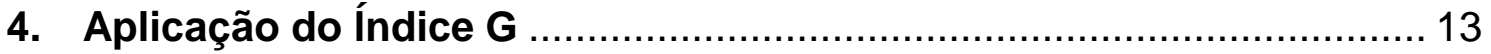

4.1. Eleitos em 2010 x Eleitos em 2014........................................ 13

4.2. Deputados Federais que buscaram a reeleição em 2014 ............. 16

5. Deputados que não Buscaram a Reeleição................................ 23

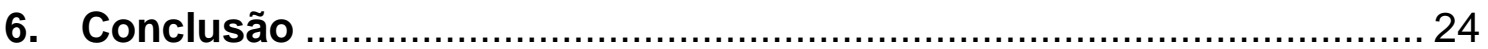

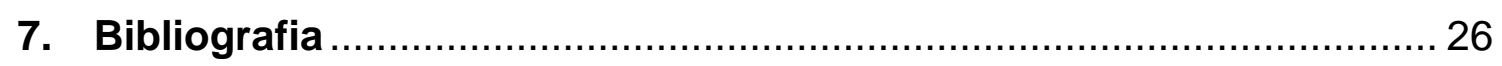




\section{INTRODUCAO}

A renovação na Câmara dos Deputados brasileira é considerada alta, girando em torno de $45 \%$ a cada nova eleição. Porém, este número não significa que novatos estão ganhando o eleitorado dos deputados, pois estes, por muitas vezes, nem sequer chegam a disputar a reeleição. Alguns vão para cargos no executivo, outros desistem da carreira política (Leoni et. al., 2004; Samuels, 2000).

A literatura acerca da reeleição de Deputados Federais trabalha com bastante ênfase nas Emendas Parlamentares, tentando mostrar que elas aumentam, ou não, as chances de o parlamentar continuar por mais um mandato. Além dessa variável, existem artigos mostrando que grande parte da alta taxa de rotatividade dos deputados brasileiros se deve ao anseio deles por pleitear cargos no executivo.

O fato é que os trabalhos dessa área visam sempre a consequência "reeleição" dada alguma causa como: Emenda Parlamentar, anseio por outros cargos, corrupção, migração partidária, concorrência etc. O presente texto vem cobrir uma lacuna existente, com foco naqueles deputados que ao tentarem a reeleição não obtiveram sucesso, ou naqueles que nem sequer tentaram um novo mandato.

O objetivo é analisar o que eles "fizeram de errado", dado que as chances de reeleição para a Câmara dos Deputados são consideravelmente elevadas (Bertholini et. al. - 2013). Será que eles se envolveram em escândalos de corrupção? Será que não souberam trabalhar em suas bases? Será que suas ações no parlamento fizeram com que perdessem apoio popular? Será que concorrentes entraram em seus territórios eleitorais?

O Brasil possui uma rotatividade menor que nos Estados Unidos. Neste, em média $97,9 \%$ dos parlamentares que tentaram a reeleição saíram vitoriosos, considerando as quatro últimas eleições para o Congresso. Isso pode ser justificado por uma série de fatores como melhor conhecimento de campanha, maiores quantidades de dinheiro, que tanto legais quanto ilegais 
aumentaram as fortunas dos congressistas, assim como pode ser justificado por ter cada vez mais cobertura de eventos políticos, trazendo maior visibilidade ao candidato à reeleição (Friedman et. al. - 2009).

Leoni et. al. (2004) faz um estudo acerca da eleição de 1998 para o Legislativo brasileiro, em que aproximadamente $80 \%$ dos Deputados Federais se candidataram a reeleição, $11 \%$ decidiram parar a carreira política e $6 \%$ buscaram postos mais elevados. A taxa de pretendentes à manutenção da cadeira na Câmara Federal é menor que nos Estados Unidos, porém maior que na maioria dos países latinos.

Isso indica que o cargo de Deputado Federal dá grande incentivo à ambição estática, em que se busca a continuidade no cargo. Porém, sem que se chegue à conclusão que aqueles políticos que acabam por permanecer no Congresso seriam mais fracos que os demais que buscam cargos superiores (Executivo ou Senado). A opção por permanecer legislando é afetada pela concorrência política, pois em locais com pequena amostra de candidatos fortes, deputados federais se sentem mais seguros para concorrer ao Senado ou a algum Governo Estadual. (Leoni et. al. - 2004)

Os autores ainda encontraram que os deputados que decidiram se candidatar a Prefeituras em 1996 tiveram maiores votações para o Congresso nas eleições de 1994 que os demais. Esse artigo é interessante por avaliar que a escolha por tentar a reeleição ou buscar outros postos não é da ambição do Deputado e sim da sua estratégia em utilizar seus recursos de maneira eficiente. Samuels (2000) vai à contramão, dizendo que metade da responsabilidade sobre a taxa de $50 \%$ de renovação na Câmara dos Deputados se deve à ambição, levando em consideração que no Brasil as posições no Executivo são mais valorizadas que as posições no Legislativo (Samuels - 2000, Bertholini et. al. - 2013).

Segundo Samuels (2000), a competitividade é responsável pela outra metade. A eleição proporcional por lista aberta seria responsável por minar o status dos atuais deputados, aumentando as chances da não reeleição. Ademais, indo à contramão da conclusão de Leoni et. al. (2004), como teoricamente os melhores deputados tentam se eleger Prefeitos, os que 
permanecem no Congresso seriam mais fracos eleitoralmente, aumentando as chances de renovação.

Samuels (2000) e Leoni et. al. (2004) apresentam resultados opostos, indicando não haver consenso absoluto quanto à ambição dos políticos e quanto à concorrência eleitoral. O presente trabalho cobrirá a janela não estudada dos Deputados que deixam de se candidatar e daqueles que perdem as eleições para manutenção de seus mandatos. Diferentemente dos trabalhos citados, o objetivo é descobrir qual o "erro" desses políticos.

Essa busca pode ter relação com o desempenho dos congressistas na Câmara dos Deputados. O artigo de Bertholini et. al. (2013) analisa este aspecto sob a ótica das Assembleias Legislativas estaduais, tomando as eleições de 2002 e 2006. Porém, os resultados encontrados nessas eleições se contradizem, indicando que mais estudos precisam ser efetuados para uma conclusão sobre o tema.

Em geral, deputados não buscam simplesmente a reeleição, mas sim a manutenção de seus postos ou a busca por colocações de mais destaque seja no Legislativo ou no Executivo. Os estudos até então mencionados sobre a capacidade eleitoral de deputados em mandato estão subdimensionando a potencialidade de votos desses políticos, pois não levam em consideração que membros da Câmara Federal possuem facilidade em assumir outros postos políticos no Brasil (De Magalhães et. al. - 2015).

Para a analisar o fracasso na reeleição de alguns deputados, a pergunta central deste trabalho é: "Por que alguns Deputados Federais diminuem consideravelmente suas votações e outros nem sequer tentam a reeleição?". Um levantamento dos dados de todos os estados brasileiros do período de 2010 a 2014 será efetuado, juntamente com uma análise quantitativa e qualitativa para capturar quais efeitos influenciaram esses políticos. Será realizado um estudo da concentração de votos do mapa de votação do candidato para capturar os efeitos da perda de territórios eleitorais ou de mudanças de estratégia em relação às campanhas. Além disso, será realizada uma pesquisa com o objetivo de buscar casos de corrupção que possam ter tido impacto na opinião do eleitorado e na mudança de objetivo dos candidatos. 
Para aqueles parlamentares que desistem de pleitear a reeleição, a hipótese levantada por este trabalho é o envolvimento em escândalos de corrupção. Com isso, a perda de apoio eleitoral faz com que a reeleição fique inviável ou que se torne um grande risco, levando o candidato à desistência.

Quanto aos Deputados Federais que perdem a reeleição em 2014, a hipótese é que a mudança na concentração de votos por município afeta os resultados. Um determinado candidato que perde concentração eleitoral pode estar expandindo suas fronteiras eleitorais ou pode estar perdendo seus territórios, levando a uma queda no número de votos. As características de cada Estado serão levadas em consideração para essa avaliação.

A próxima seção trata da metodologia a ser adotada, além de trazer alguns artigos que trabalham com mapas e concentração eleitoral. A seção 3 versa sobre a metodologia adotada e apresenta a teoria acerca de concentração eleitoral. A seção 4 apresenta os dados já compilados e faz a análise devida para provar as hipóteses levantadas. A seção 5 trata dos Deputados Federais que não quiseram pleitear a reeleição e a seção 6 conclui o trabalho, apresentando os resultados obtidos e sugerindo futuros estudos.

\section{Sistemas Eleitorais}

São muitos os sistemas eleitorais para escolha dos eleitos do legislativo de um país. Esta seção tem por objetivo mostrar suscintamente cada tipo de sistema e focar no sistema proporcional por lista aberta, que é o utilizado pelo Brasil.

Bormann e Golder dividem os sistemas eleitorais legislativos em três categorias: majoritário, proporcional e misto. No majoritário, basicamente aquele candidato que recebe mais votos é eleito, assim como acontece nas eleições para o executivo brasileiro, obviamente podendo conter variações (Bormann et. al., 2013).

No sistema eleitoral proporcional, nem sempre o candidato mais votado é eleito. Existem diferentes variantes, mas no Brasil é utilizada a lista aberta, em que cada partido apresenta uma lista de candidatos. O eleitor pode votar na 
legenda (coligação) ou em um candidato específico. Este último voto também soma para a coligação, que conquista as cadeiras no legislativo, as quais serão ocupadas pelos candidatos mais bem votados da coligação.

No sistema misto, como o próprio nome já diz, são eleitos representantes tanto pelo sistema majoritário quanto proporcional. Esse método pode ter duas votações independentes entre si, ou com vínculo.

Uma das variações do sistema proporcional por lista aberta é por divisor, em que são utilizados diversos tipos de cálculo para a obtenção das cadeiras conquistadas por cada coligação. No Brasil é utilizado o método D'Hondt, que é o método mais utilizado ao redor do mundo.

\subsection{Sistema Eleitoral Brasileiro}

Nas eleições para a Câmara dos Deputados, cada Estado da Federação possui um número determinado de cadeiras, que variam de 8 a 70. Os Estados com menor população possuem menos Deputados, porém possuem maior número quando analisado de forma proporcional. Da mesma forma, os Estados com maior número de habitantes ficam com número proporcional inferior.

No total, são 513 Deputados Federais que disputam entre si dentro de seus respectivos estados por meio de votação proporcional por lista aberta. $O$ Brasil é o país que há mais tempo utiliza esse sistema eleitoral (Nicolau, J. 2006).

A legislação não limita o número de reeleições e os eleitores podem votar em um candidato específico ou em uma legenda, somando votos para a chapa de deputados da coligação a que faz parte.

O voto proporcional segue a regra do Quociente Eleitoral (D'hondt Representação proporcional por lista aberta), que nada mais é do que a soma da quantidade de votos dividida pelo número de cadeiras a serem ocupadas. Toma-se a soma de votos de uma coligação, o seu número de vagas será o número inteiro da divisão dos seus votos pelo quociente eleitoral, com arredondamento da fração para 0 , se menor ou igual a meio e 1 , se superior. 
Determina-se o quociente eleitoral dividindo-se o número de votos válidos apurados pelo de lugares a preencher em cada circunscrição eleitoral, desprezada a fração se igual ou inferior a meio, equivalente a um, se superior (Artigo 106, do Código Eleitoral).

Determina-se para cada Partido ou coligação o quociente partidário, dividindo-se pelo quociente eleitoral o número de votos válidos dados sob a mesma legenda ou coligação de legendas, desprezada a fração (Artigo 107, do Código Eleitoral).

Depois desse procedimento, se ainda ficar cadeira vaga, o ocupante será da coligação que estiver com a maior "média", divisão entre seus votos e o número de cadeiras já entregues à coligação mais um. Se ainda ficarem posições vagas, o mesmo procedimento é realizado até que se esgotem as cadeiras.

\begin{abstract}
Dividir-se-á o número de votos válidos atribuídos a cada partido ou coligação pelo número de lugares definido para o partido pelo cálculo do quociente partidário do art. 107, mais um, cabendo ao partido ou coligação que apresentar a maior média um dos lugares a preencher, desde que tenha candidato que atenda à exigência de votação nominal mínima (Inciso I, do art. 109, do Código Eleitoral);
\end{abstract}

Repetir-se-á a operação para cada um dos lugares a preencher (Inciso II, do art. 109, do Código Eleitoral);

Quando não houver mais partidos ou coligações com candidatos que atendam às duas exigências do inciso $I$, as cadeiras serão distribuídas aos partidos que apresentem as maiores médias (Inciso III, do art. 109, do Código Eleitoral).

No Brasil existe um ponto de corte que exclui da disputa as coligações que não conseguem obter o número de votos do quociente eleitoral (Parágrafo 2; do Artigo 109; do Código Eleitoral). Além disso, a partir das eleições de 2016, um candidato não poderá se eleger se possuir menos que $10 \%$ dos votos do Quociente Eleitoral (Artigo 108; do Código Eleitoral). Esse corte foi instituído para evitar candidatos eleitos com baixíssima votação, que acabam sendo puxados por legisladores eleitos com votações expressivas.

$\mathrm{Na}$ eleição para o legislativo brasileiro há competição entre candidatos de partidos diferentes, mas também de candidatos do mesmo partido, o que faz com que se tenha um enfraquecimento das legendas, valendo mais o voto individual. Isso acaba por enfraquecer os partidos políticos (Finan, Mazzocco, 2015). Esse fenômeno ajuda a explicar o excessivo número de partidos políticos no Brasil. 
Atualmente, existe uma lei que proíbe a troca de partido pelos Deputados com mandato. Esta proibição se baseia no entendimento que o cargo é do partido e não do indivíduo. Porém, a troca partidária ainda é possível se tiver havido fusão ou criação de uma nova legenda, ou ainda por justa causa ao ter um desvio reiterado do programa partidário ou grave discriminação pessoal (TSE, Resolução, 2007).

Do ponto de vista prático, os Deputados brasileiros tiveram suas funções desviadas, pois um parlamentar obtém sucesso eleitoral se ele consegue entregar recursos financeiros para a população da sua base, e não pela sua forma de legislar, que não possui tanta importância para o sucesso eleitoral (Finan, Mazzocco, 2015).

\section{Metodologia}

Para a análise do período a ser tratado neste trabalho, foram utilizados os microdados eleitorais disponíveis no site do Tribunal Superior Eleitoral (TSE). As reeleições para a Câmara Federal a serem avaliadas são as de 2014, por isso foi necessário capturar os dados de 2010 e de 2014 para a avaliação.

Será utilizado o índice de concentração proposto por Biderman et. al. (2011), o índice $G$, que se mostrou mais adequado para comparações entre anos e candidatos diferentes. A próxima subseção versará sobre os dados, já apresentando alguns números relacionados às eleições de 2010 e de 2014. A subseção 3.2 tratará da literatura acerca de mapas eleitorais e de concentração dos votos recebidos por políticos.

\subsection{Dados}

Os primeiros resultados estão apresentados na Tabela 1. Seguindo o que a literatura indicava, o Brasil apresentou em 2014, alto índice de renovação, pois praticamente metade dos eleitos para Câmara Federal não tinham sido eleitos em 2010. Vale ressaltar que nesta análise não foram 
considerados os Deputados que assumiram uma cadeira como suplente, estes foram considerados derrotados na eleição de 2010.

Tabela 1 - Status dos Deputados em 2014

\begin{tabular}{l|c|c}
\hline \multicolumn{1}{c|}{ Resultado } & Qtde. de Deputados & Proporção \\
\hline Se reelegeu & 264 & $51 \%$ \\
\hline Perdeu a reeleição & 87 & $17 \%$ \\
\hline Não se candidatou & 70 & $14 \%$ \\
\hline Buscou outros cargos & 68 & $13 \%$ \\
\hline Se tornou Prefeito & 24 & $5 \%$ \\
\hline
\end{tabular}

Fonte: Elaborado pelo autor, a partir de dados do TSE.

No ano de $2014,68 \%$ dos parlamentares tentaram a reeleição, $14 \%$ não se candidataram a nenhum posto, $13 \%$ pleitearam outros cargos eletivos, enquanto $5 \%$ foram eleitos prefeitos nas eleições de 2012. Considerando apenas os parlamentares que tentaram a reeleição, $75 \%$ obtiveram êxito, contra $25 \%$ que saíram derrotados do pleito. Essa taxa de sucesso é baixa quando comparada aos Estados Unidos, em que 97,9\% são reeleitos (Friedman et. al. - 2009). Porém, ainda mostra a vantagem eleitoral de quem já está no posto.

Entre os $13 \%$ que pleitearam outros cargos em 2014 , estão os que se candidataram a governador e vice-governador, a senador ou suplente de senador ou a deputado estadual. Desses, a maioria (31\%), tentou uma vaga no Senado Federal, enquanto $28 \%$ tentaram se eleger na chapa ao governo como vice-governadores. Candidataram-se a Deputado Estadual 19\% dos que pleitearam outros cargos, sendo que $62 \%$ obtiveram êxito para as Assembleias Legislativas.

Leoni et. al. (2004) avalia a candidatura de um Deputado Federal a uma Assembleia Legislativa como ambição regressiva, já que o parlamentar estaria concorrendo a um cargo de menor nível e de menor risco. Os autores consideram que a perspectiva de derrota ao tentar a reeleição leva certos congressistas a buscarem o cargo de Deputado Estadual. Como mencionado, $75 \%$ dos que concorreram à reeleição foram eleitos e apenas $62 \%$ dos que 
tentaram os parlamentos estaduais conquistaram uma cadeira. Isso prova a teoria dos autores de que estes deputados buscam as Assembleias por estarem mais enfraquecidos, com menos chances de vitória.

Dos setenta deputados que não se candidataram a nenhum cargo eletivo, sete indicaram parentes próximos para a vaga. Seis indicaram e apoiaram os filhos e um apoiou um sobrinho. Nessa reposição familiar, $86 \%$ obtiveram êxito, demonstrando o poder do sobrenome nas eleições para 0 legislativo no Brasil. Mais da metade desses herdeiros políticos conseguiram alcançar votações semelhantes aos seus pais ou tio. Enquanto o restante sofreu uma queda significativa no número de eleitores.

Destes parentes de políticos que tentaram se eleger, três se candidataram pelo fato dos pais estarem envolvidos em escândalos de corrupção. Ainda assim, dois desses três candidatos foram eleitos, o que deixa clara a facilidade de manutenção de votos de um Deputado Federal, pois mesmo com envolvimento evidenciado pela mídia, conseguiram emplacar filhos às cadeiras da Câmara Federal.

O êxito na reeleição é menor, proporcionalmente, entre os candidatos que foram eleitos por média na eleição anterior. Neste caso, dos que se candidataram $53 \%$ conseguiram se reeleger, enquanto $47 \%$ saíram derrotados. Entre os que foram eleitos por quociente partidário, $78 \%$ se reelegeram e $22 \%$ perderam a disputa.

Os 264 candidatos à reeleição na Câmara Federal que foram eleitos, representam uma renovação de quase $50 \%$ das cadeiras dessa casa legislativa. $\mathrm{Na}$ disputa pela continuidade no cargo, 129 Deputados vitoriosos conseguiram melhorar suas votações, em números absolutos, em relação à eleição de 2010. Porém, apesar da vitória, 135 parlamentares apresentaram queda nominal no número de eleitores.

\subsection{Mapa e Concentração Eleitoral}

Um aspecto bastante estudado no que se refere à reeleição de Deputados Federais é a utilização de Emendas Parlamentares como forma de 
Pork para angariar apoio político para o próximo período eleitoral. É interessante notar que existem diferentes tipos de Deputados, aqueles que possuem apoio disperso pelo território estadual e aqueles que possuem apoio concentrado em um ou alguns poucos municípios (Ames - 1995; Nunes 2010).

Essas duas características geográficas ainda podem se dividir de diversas formas. Uma delas é quanto ao domínio eleitoral do candidato. Ele pode ter a votação localizada e ser o primeiro em sua região, ou não ser o líder. Assim como ele pode ser um político com votação dispersa mediana ou votação dispersa com liderança. Todos esses tipos de configurações geográficas são tratados por Barry Ames (1995), inclusive as diferenças intrínsecas dos diversos estados brasileiros.

O mapa eleitoral, ou mapa de votos de candidatos ou partidos, se constitui de uma importante ferramenta para a análise de eleições, pois a partir dele podemos considerar os investimentos realizados por Deputados por meio de Emendas Parlamentares, assim como a concorrência e região de cada Candidato à Câmara Federal (Ames - 1995).

Barry Ames (1995) analisou esse mapa, juntamente com emendas parlamentares, para chegar a algumas conclusões sobre estratégias eleitorais e o consequente sucesso em utilizá-las. Os dados foram retirados das eleições de 1986 e de 1990.

O autor desenvolveu uma teoria para explicar o comportamento eleitoral e distribuição espacial dos votos para os candidatos à Câmara dos Deputados. Ele utilizou modelos para entender onde os Deputados aplicam suas Emendas Parlamentares para beneficiar certos municípios em que almejam maior número de votos na próxima eleição.

Em sua hipótese, elencou seis pontos que influenciam na escolha dos municípios a serem buscados por cada político: O custo de barreiras para a entrada; o domínio do Deputado na região; a concentração dos votos considerando todo o Estado; a vulnerabilidade do município para a entrada de concorrentes; as fraquezas do Candidato na última eleição; e o histórico político do homem público em questão. 
Para a análise, Barry Ames utiliza uma regressão logística em que considera a existência ou não do pedido de Emenda Parlamentar para um dado munícipio, sem considerar o valor desta emenda. Os resultados mostram que os candidatos procuram regiões seguras para si, além de tentarem entrar em municípios vulneráveis, que seriam aqueles que tiveram uma mudança no perfil do eleitor (grande número de imigrantes, etc). Os Deputados tentam se sobressair entregando Pork, estrutura que os próprios eleitores se acostumaram em detrimento de programas partidários ou ideológicos.

O autor enfatiza a falta de compromisso partidário e de ideais no Congresso Nacional, mostrando que seus membros agem estrategicamente durante seus mandatos para conseguirem mais apoio dos eleitores, seja buscando municípios vulneráveis eleitoralmente ou localidades seguras, sempre por intermédio de Pork (Emendas Parlamentares).

Como estratégia de campanha, além de gastarem muito dinheiro, os candidatos fazem acordos com outros que nada tem em comum. Estas são as chamadas "dobradinhas" que unem postulantes a Deputado Estadual e Federal com o objetivo de repassar votos de sua região para o outro. Porém, essa união é meramente eleitoral, sem nenhum vínculo ideológico.

Os resultados do autor mostram ainda que deputados com lideranças municipais são mais tendentes a entregar emendas às suas localidades. Tal efeito é notado também entre os candidatos mais bem ranqueados na eleição de 1986 (Ames - 1995).

Seguindo a mesma linha, Firpo et. al. (2015) estuda as Emendas Parlamentares e mostra a relação entre Deputados e suas regiões. Porém, chega ao resultado de que as emendas destinadas a locais fora do território eleitoral de um dado Deputado possui maior impacto nos votos. Além disso, não conseguiu confirmar se esses benefícios orçamentários aumentam a chance de reeleição, ou seja, não é fator determinante para o sucesso político.

Mesquita (2008) não conseguiu sequer identificar um padrão na alocação das emendas individuais. Ela considerou dados das reeleições de 1998, 2002 e 2006 para concluir que cada parlamentar adota estratégias próprias de acordo com a trajetória política individual e suas ambições. Esse 
resultado contradiz Barry Ames no que se refere à existência de estratégias dominantes.

Se as Emendas não trazem sucesso eleitoral, qual o motivo de serem tão utilizadas? Uma possibilidade é que os políticos não buscam votos com as emendas, e sim dinheiro. Na execução das mesmas, o dinheiro é repassado para poderes econômicos locais, que beneficiariam o candidato na próxima eleição (Samuels, 2002).

O presente trabalho não entrará na questão das Emendas Parlamentares, mas realizará uma análise da mudança na concentração eleitoral de alguns candidatos à reeleição derrotados. O objetivo é identificar se existe alguma alteração comum entre os candidatos, como por exemplo uma maior desconcentração eleitoral.

Existem diversos índices de concentração que poderiam ser utilizados, Biderman et. al. (2011) apresenta três diferentes índices de concentração e propõe um quarto, denominado $G_{d}$, que será o utilizado neste trabalho. A justificativa pela sua utilização é semelhante à dos autores, já que este seria o índice que melhor faz a comparação entre candidatos e eleições em anos diferentes.

A notação aqui utilizada é a mesma do trabalho previamente mencionado:

$$
G_{d}=\sum_{m}\left(\frac{V_{d m}}{V_{d}}-\frac{V_{m}}{V}\right)^{2}
$$

- $\mathrm{V}_{\mathrm{dm}}$ - votos do deputado d no município $\mathrm{m}$

- $\mathrm{V}_{\mathrm{d}}=\sum_{\mathrm{m}} \mathrm{V}_{\mathrm{dm}}$ - votos do deputado d em todo o Estado

- $\mathrm{V}_{\mathrm{m}}=\sum_{\mathrm{d}} \mathrm{V}_{\mathrm{dm}}$ - votos válidos no município $\mathrm{m}$

- $\mathrm{V}=\sum \sum \mathrm{V}_{\mathrm{dm}}-$ votos válidos em todo o Estado

O índice de concentração proposto pelos autores é uma pequena adaptação do Índice G, amplamente utilizado na área de economia regional. Ele se mostra adequado, pois trata da diferença entre a proporção de votos recebida por determinado candidato em um município e a proporção de votos 
do município. Ou seja, se o candidato em questão tivesse sua votação perfeitamente desconcentrada, o índice seria 0.

Com isso, é possível fazer comparações entre diferentes candidatos, assim como comparações temporais para analisar as mudanças na concentração do mapa eleitoral de determinado candidato à Câmara Federal.

\section{Aplicação do Índice G}

O índice apresentado foi utilizado para diversas análises das concentrações dos candidatos à Câmara Federal. É importante notar a ausência de deputados do Distrito Federal no estudo. Isso porque Brasília é o único município daquela localidade, logo os índices de concentração serão sempre zero, o que impossibilita a análise por esse caminho. Portanto, serão 505 cadeiras da Câmara Federal em estudo.

A próxima subseção faz a comparação entre os eleitos em 2010 e os eleitos em 2014. A subseção 4.2 irá analisar os deputados que buscaram a reeleição em 2014.

\subsection{Eleitos em 2010 x Eleitos em 2014}

O objetivo central deste trabalho é analisar os deputados que foram derrotados nas eleições de 2014 ao tentarem se reeleger. Porém, é importante analisar como se comportaram as estatísticas eleitorais daqueles que foram eleitos para que tenhamos uma variável de comparação.

A primeira verificação a ser feita com o índice $G$ será a comparação entre os candidatos a Deputado Federal que foram eleitos em 2010 e os que foram eleitos em 2014 em todo o Brasil. A Tabela 2 resume os dados indicando uma leve desconcentração de uma eleição para a outra com queda de aproximadamente $4 \%$ no índice. 
Tabela 2 - Brasil - Índice G para eleitos em 2010 e em 2014

\begin{tabular}{l|c|c|c}
\hline \multirow{2}{*}{ Situação } & \multirow{2}{*}{ Medida } & \multicolumn{2}{c}{ Ano } \\
\cline { 3 - 4 } & & $\mathbf{2 0 1 0}$ & $\mathbf{2 0 1 4}$ \\
\hline \multirow{2}{*}{ Eleitos } & Média & 0,096 & 0,092 \\
& Obs & 505 & 505 \\
\hline \multirow{2}{*}{ Eleitos por Qp } & Média & 0,094 & 0,088 \\
& Obs & 440 & 434 \\
\hline \multirow{2}{*}{ Eleitos por média } & Média & 0,109 & 0,119 \\
& Obs & 65 & 71 \\
\hline
\end{tabular}

Fonte: Elaborado pelo autor, a partir de dados do TSE.

É importante notar as diferenças entre os diferentes distritos eleitorais (Estados) do país. Deixando para outro estudo a parte socioeconômica e populacional, faremos a análise por Estado sob o aspecto do número de cadeiras para a Câmara Federal. O Estado de São Paulo tem direito a eleger 70 deputados, enquanto outros dez estados, principalmente do Centro-Oeste e do Norte, podem eleger apenas 8.

Essa diferença na quantidade de vagas destinadas a cada Estado faz com que os candidatos adotem estratégias distintas para tentarem a eleição. Um distrito com 70 vagas torna possível a eleição de um candidato que tenha votos de menos de 1,5\% do eleitorado. Enquanto em um Estado com 8 vagas disponíveis faz essa porcentagem aumentar para 12,5\%. Portanto, Estados com maior número de cadeiras dão incentivo a se ter uma maior concentração eleitoral para a diminuição de custos (Biderman et. al., 2011).

A Tabela 3 é semelhante à Tabela 2, mas com apenas os eleitos do Estado de São Paulo, distrito com o maior número de cadeiras na Câmara. É notável que a concentração nesse Estado é bem superior à média, chegando a quase $60 \%$ a mais em 2014. Outro ponto importante para a análise se dá pelo fato da concentração ter aumentado de uma eleição para outra, indo na contramão da média brasileira. A alta variação na concentração dos eleitos por média se dá pelo baixo número de observações, fazendo com que um candidato fora dos parâmetros normais influencie muito na média. Por exemplo, em 2014 um candidato eleito por média chegou a atingir 0,962 em 
seu índice G, ou seja, foi praticamente eleito em apenas um município, o que é incomum e acabou por distorcer o índice.

Para fazer o contraponto com São Paulo, a Tabela 4 traz a média do Índice de Concentração para os candidatos eleitos dos dez Estados brasileiros que possuem direito a 8 cadeiras na Câmara Federal. Ao contrário do Estado anteriormente analisado, esses distritos eleitorais possuem índice $G$ aproximadamente $34 \%$ abaixo do valor da média nacional. Como a proporção de votos a ser buscada é bem superior, a necessidade de conseguir uma desconcentração no mapa de votação é essencial para o êxito eleitoral.

Tabela 3 - São Paulo - Índice G para eleitos em 2010 e em 2014

\begin{tabular}{l|c|c|c}
\hline \multirow{2}{*}{ Situação } & \multirow{2}{*}{ Medida } & \multicolumn{2}{c}{ Ano } \\
\cline { 3 - 4 } & & $\mathbf{2 0 1 0}$ & $\mathbf{2 0 1 4}$ \\
\hline \multirow{2}{*}{ Eleitos } & Média & 0,131 & 0,146 \\
& Obs & 70 & 70 \\
\hline \multirow{2}{*}{ Eleitos por Qp } & Média & 0,134 & 0,131 \\
& Obs & 64 & 62 \\
\hline \multirow{2}{*}{ Eleitos por média } & Média & 0,090 & 0,267 \\
& Obs & 6 & 8 \\
\hline
\end{tabular}

Fonte: Elaborado pelo autor, a partir de dados do TSE.

Tabela 4 - Estados com 8 cadeiras - Índice G para eleitos em 2010 e em 2014

\begin{tabular}{l|c|c|c}
\hline \multirow{2}{*}{ Situação } & \multirow{2}{*}{ Medida } & \multicolumn{2}{c}{ Ano } \\
\cline { 3 - 4 } & & $\mathbf{2 0 1 0}$ & $\mathbf{2 0 1 4}$ \\
\hline \multirow{2}{*}{ Eleitos } & Média & 0,062 & 0,062 \\
& Obs & 80 & 80 \\
\hline \multirow{2}{*}{ Eleitos por Qp } & Média & 0,054 & 0,058 \\
& Obs & 65 & 62 \\
\hline \multirow{2}{*}{ Eleitos por média } & Média & 0,096 & 0,073 \\
& Obs & 15 & 18 \\
\hline
\end{tabular}

Fonte: Elaborado pelo autor, a partir de dados do TSE.

Essas características de cada Estado da Federação devem ser notadas para a avaliação de perda ou ganho de votos em eleições subsequentes para o 
mesmo cargo. Portanto, seguindo o objetivo do trabalho, iremos analisar aqueles deputados que foram eleitos em 2010 e que buscaram a reeleição em 2014. O objetivo é avaliar se a mudança no índice $G$ é diferente entre os que obtiveram êxito e os que fracassaram na tentativa de reeleição.

\subsection{Deputados Federais que buscaram a reeleição em 2014}

Esta subseção irá avaliar aqueles deputados que buscaram a reeleição em 2014. O objetivo é entender o motivo de parte deles não terem conseguido a vitória. A hipótese levantada foi quanto à perda de concentração eleitoral, segundo Biderman et. al. (2011), candidatos muito concentrados que se elegem tendem a se desconcentrar e a perder a eleição seguinte para 0 mesmo cargo.

A Tabela 5 apresenta a média do índice $G$ para os parlamentares que buscaram permanecer na casa. A queda no grau de concentração é de aproximadamente $17 \%$ de um ano para o outro, sendo maior entre os não eleitos. A média do índice para os deputados derrotados em 2014 é aproximadamente $35 \%$ maior do que a média daqueles que se reelegeram.

Tabela 5 - Brasil - Índice G para os que tentaram a reeleição em 2014

\begin{tabular}{l|c|c|c}
\hline \multirow{2}{*}{ Situação } & \multirow{2}{*}{ Medida } & \multicolumn{2}{|c}{ Ano } \\
\cline { 3 - 4 } Todos & & $\mathbf{2 0 1 0}$ & $\mathbf{2 0 1 4}$ \\
\hline \multirow{2}{*}{ Eleitos } & Média & 0,094 & 0,078 \\
Obs & \multicolumn{2}{|c}{347} \\
\hline Eleitos por Qp & Média & 0,086 & 0,072 \\
Obs & \multicolumn{2}{|c}{261} \\
\hline Eleitos por Média & $\begin{array}{c}\text { Média } \\
\text { Obs }\end{array}$ & 0,085 & 0,071 \\
\hline Não Eleitos & $\begin{array}{c}\text { Média } \\
\text { Obs }\end{array}$ & 0,095 & 0,081 \\
\hline & Média & 0,118 & 0,097 \\
\hline
\end{tabular}

Fonte: Elaborado pelo autor, a partir de dados do TSE. 
Um aspecto fundamental para este tipo de análise é verificar o perfil de alguns deputados. A Tabela 6 descreve o grau de concentração municipal dos candidatos novatos, que estrearam na Câmara Federal em 2010 e que tentaram a reeleição em 2014. Foram considerados novatos aqueles que não haviam disputado uma eleição estadual antes, seja para Deputado Federal ou Estadual, Senador, ou para o Governo.

É notável a diferença do Índice $G$ dos que conseguiram se reeleger para os que não obtiveram êxito na reeleição. Estes eram mais concentrados, sendo mais vulneráveis a choques externos. Outro ponto importante de se notar é a quantidade de fracasso na reeleição entre os membros desse grupo. Isso indica a dificuldade dos novatos na Câmara Federal que não assumiram cargos eletivos a nível estadual anteriormente. Praticamente $74 \%$ dos novatos que tentaram a reeleição tiveram que deixar o parlamento.

Tabela 6 - Brasil - Análise dos novatos de 2010 na reeleição de 2014

\begin{tabular}{l|c|c|c}
\hline \multirow{2}{*}{ Situação } & \multirow{2}{*}{ Medida } & \multicolumn{2}{c}{ Ano } \\
\cline { 3 - 4 } Novatos & & $\mathbf{2 0 1 0}$ & $\mathbf{2 0 1 4}$ \\
\hline \multirow{2}{*}{ Eleitos } & Média & 0,078 & 0,072 \\
Obs & \multicolumn{2}{|c}{23} \\
\hline \multirow{2}{*}{ Não Eleitos } & Média & 0,031 & 0,048 \\
\hline
\end{tabular}

Fonte: Elaborado pelo autor, a partir de dados do TSE.

Como a eleição no Brasil é proporcional, acontece de ter candidatos à reeleição com votações inferiores às obtidas anteriormente, assim como pode acontecer de um deputado aumentar sua votação, mas não conseguir se reeleger. Portanto, a Tabela 7 é importante para avaliar sob esse aspecto e não somente pelo resultado eleito/não eleito.

Pelos resultados apresentados na tabela, os deputados que ganharam mais eleitores apresentaram significativamente maior número de desconcentração eleitoral. Esse resultado indica a importância de um Deputado 
Federal ter seu voto mais disperso no território do Estado e não somente em cidades específicas.

Tabela 7 - Brasil - Concentração eleitoral de acordo com aumento/diminuição de votos

\begin{tabular}{l|c|c|c}
\hline Resultado da Reeleição & Total & Desconcentraram & Concentraram \\
\hline Menos Eleitores & 213 & $111(52 \%)$ & $102(48 \%)$ \\
\hline Mais Eleitores & 134 & $88(66 \%)$ & $46(34 \%)$ \\
\hline
\end{tabular}

Fonte: Elaborado pelo autor, a partir de dados do TSE.

Esta mesma análise foi realizada com a comparação entre o Estado de São Paulo e o conjunto dos 10 Estados que possuem 8 cadeiras cada. A Tabela 8 e a Tabela 9 impressionam por mostrarem diferenças de perfil entre os Estados brasileiros. A primeira apresenta os candidatos à reeleição de São Paulo, em que os resultados são próximos e pouco conclusivos. Porém, a segunda mostra uma enorme vantagem em se buscar a desconcentração eleitoral em alguns Distritos Eleitorais. Isso porque grande parte dos candidatos que aumentaram suas votações apresentou grande tendência à desconcentração entre municípios. Pelo outro lado, aqueles que perderam eleitores apresentaram, em sua maioria, concentração eleitoral.

Tabela 8 - São Paulo - Concentração eleitoral de acordo com aumento/diminuição de votos

\begin{tabular}{l|c|c|c}
\hline Resultado da Reeleição & Total & Desconcentraram & Concentraram \\
\hline Menos Eleitores & 35 & $20(57 \%)$ & $15(43 \%)$ \\
\hline Mais Eleitores & 14 & $7(50 \%)$ & $7(50 \%)$ \\
\hline
\end{tabular}

Fonte: Elaborado pelo autor, a partir de dados do TSE. 
Tabela 9 - Estados com 8 cadeiras - Concentração eleitoral de acordo com aumento/diminuição de votos

\begin{tabular}{l|c|c|c}
\hline Resultado da Reeleição & Total & Desconcentraram & Concentraram \\
\hline Menos Eleitores & 30 & $10(33 \%)$ & $20(67 \%)$ \\
\hline Mais Eleitores & 14 & $10(71 \%)$ & $4(29 \%)$ \\
\hline
\end{tabular}

Fonte: Elaborado pelo autor, a partir de dados do TSE.

A Tabela 10 apresenta aqueles candidatos que se mostraram muito concentrados na eleição de 2010. Para a seleção, foram considerados "muito concentrados" aqueles que apresentaram índice G em 2010 acima de um desvio padrão da média relativa a todos os candidatos de 2010 que tentaram a reeleição em 2014.

É possível notar que nesse universo os que mais conseguiram se desconcentrar em termos de distribuição municipal, foram os que obtiveram incremento em suas votações. Na média, todos ficaram mais desconcentrados, mas os que tiveram mais votos em 2014 que em 2010 mostraram terem conseguido maior capilaridade.

Tabela 10 - Candidatos à Reeleição muito concentrados (acima de um desvio padrão da média)

\begin{tabular}{l|c|c|c}
\hline \multirow{2}{*}{ Situação } & \multirow{2}{*}{ Medida } & \multicolumn{2}{|c}{ Ano } \\
\cline { 3 - 4 } & & $\mathbf{2 0 1 0}$ & $\mathbf{2 0 1 4}$ \\
\hline \multirow{2}{*}{ Todos } & Média & 0,384 & 0,276 \\
\hline Obs & \multicolumn{2}{|c}{37} \\
\hline Perderam Votos & Média & 0,382 & 0,302 \\
\hline Ganharam Votos & Obs & \multicolumn{2}{|c}{21} \\
\hline & $\begin{array}{c}\text { Média } \\
\text { Obs }\end{array}$ & 0,386 & 0,241 \\
\hline
\end{tabular}

Fonte: Elaborado pelo autor, a partir de dados do TSE. 
Uma outra análise interessante é avaliar para aqueles Deputados que tiveram uma queda drástica de um ano para outro e acabaram por não se reeleger. Para a seleção do limiar de perda de votos que seria aplicado para o estudo de tais deputados, foram consideradas as quedas relativas de votação de todos os deputados que buscaram a reeleição e perderam número de votos.

$$
\mathrm{Q}_{\mathrm{d}}=\frac{\mathrm{V}_{\mathrm{d}}^{2014}}{\mathrm{~V}_{\mathrm{d}}^{2010}}-1
$$

- $\mathrm{Q}_{\mathrm{d}}$ - Percentual de queda da eleição de 2010 para 2014

- $V_{d}^{a}$ - Votação do deputado d no ano a

Dos 350 deputados federais que tentaram a reeleição, 214 tiveram queda em suas votações. A queda média $\left(Q_{\text {média }}\right)$ foi de $28 \%$, com um desvio padrão de 19\%. Para esta análise, foram consideradas quedas significativas aquelas que ultrapassaram um desvio padrão da média, ou seja, os deputados que que apresentaram queda maior que $47 \%$ e que não foram reeleitos, entraram no estudo.

Vale ressaltar que sete congressistas tiveram queda maior que $47 \%$ e ainda assim conseguiram se reeleger. Estes não entraram no estudo, já que o objetivo é avaliar aqueles que sofreram revés eleitoral, que foram vinte e quatro parlamentares de quatorze estados diferentes.

O resultado apresentou certa tendência de desconcentração eleitoral entre os candidatos que perderam significativo número de votos. Desses, $58 \%$ obtiveram uma votação mais desconcentrada em 2014, enquanto $42 \%$ tiveram seu mapa eleitoral mais concentrado (Figura 1). 


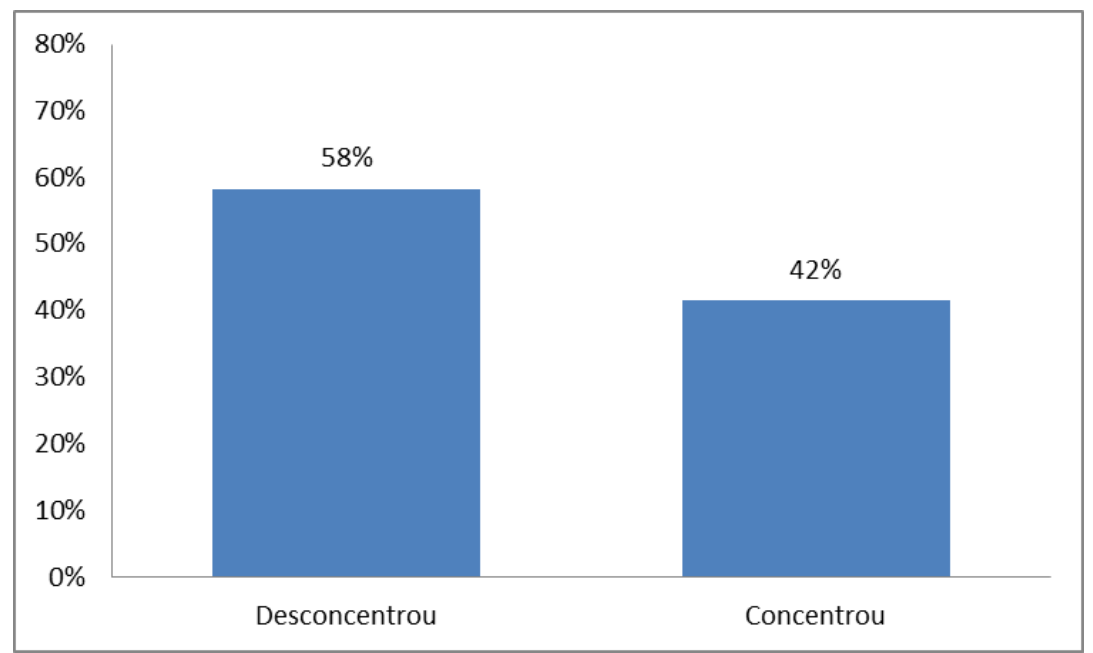

Figura 1 - Alteração na concentração eleitoral dos candidatos à reeleição que perderam significativo número de votos para a Câmara Federal

Fonte: Elaborado pelo autor, a partir de dados do TSE.

Essa desconcentração pode ser resultado da perda de apoio político em seus principais centros eleitorais. Talvez pela entrada de outro forte candidato ou talvez por ter se envolvido em algum escândalo. É importante frisar que esse índice de concentração se refere a municípios apenas. Portanto, não capta informação de concentração em regiões do estado, como municípios vizinhos ou áreas metropolitanas.

Tomando as regiões Sul, Sudeste e Centro-Oeste o resultado difere e a variação com face à desconcentração eleitoral se torna evidente. Essas regiões englobam treze candidatos à reeleição que tiveram uma queda de mais de $47 \%$ em suas votações. Destes, $69 \%$ apresentaram desconcentração, ou seja, suas votações ficaram mais aleatórias entre os municípios (Figura 2).

A Figura 3 mostra o mesmo dado, mas para as regiões Norte e Nordeste. Nessas localidades, nota-se maior número de deputados apresentando concentração eleitoral. Como era de se esperar, as regiões apresentam resultados distintos entre elas, já que em cada uma a estratégia de eleição se dá de formas diferentes. 


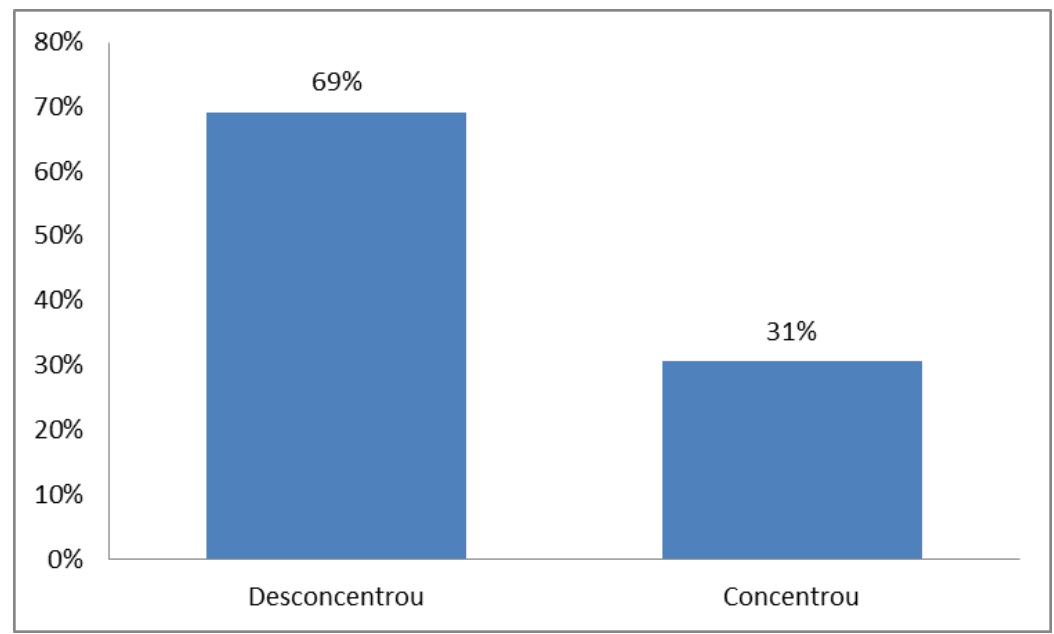

Figura 2 - Alteração na concentração eleitoral dos candidatos à reeleição do Sul, Sudeste e Centro-Oeste que perderam significativo número de eleitores

Fonte: Elaborado pelo autor, a partir de dados do TSE.

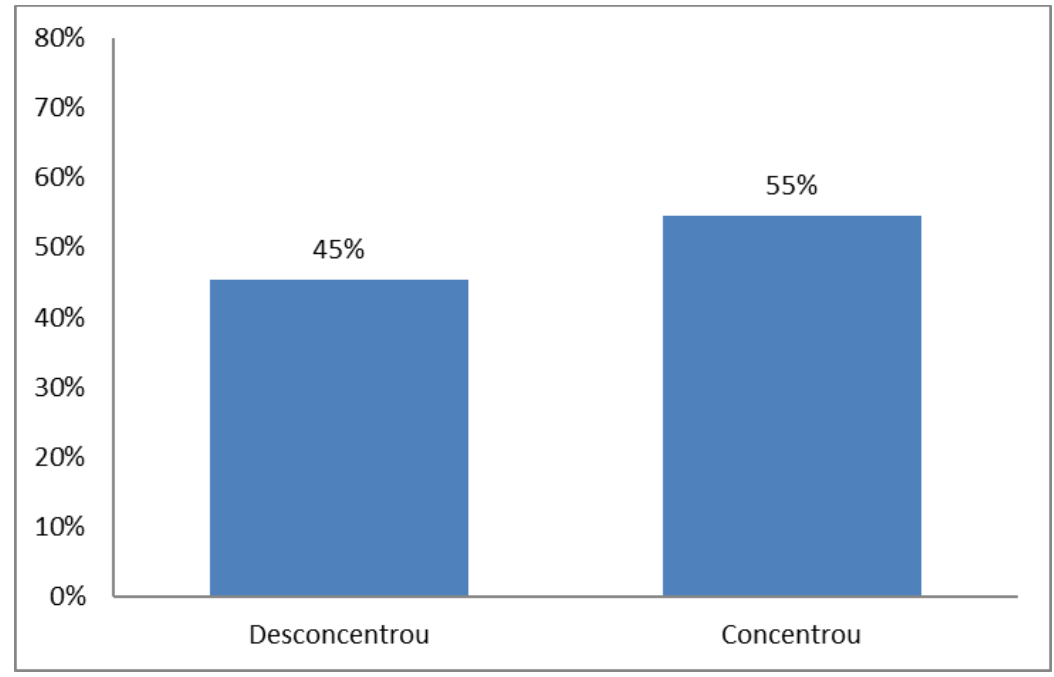

Figura 3 - Alteração na concentração eleitoral dos candidatos à reeleição do Norte e Nordeste que perderam significativo número de eleitores

Fonte: Elaborado pelo autor, a partir de dados do TSE.

Os resultados apresentados nesta seção mostram que existem diferenças significativas entre os Estados e Regiões do Brasil no que se refere às estratégias eleitorais. Nos estados em que o número de vagas para a Câmara Federal é pequeno, a desconcentração eleitoral leva a melhores 
resultados, enquanto que nos estados onde o número de cadeiras é alto, a desconcentração eleitoral prejudica os candidatos. Neste caso, a concentração é benéfica.

\section{Deputados que não Buscaram a Reeleição}

São diversas as possibilidades para um Deputado federal deixar de se candidatar a qualquer cargo eletivo ao final do seu mandato. Em 2014 foram setenta parlamentares que preferiram ficar de fora da disputa eleitoral. Porém, $10 \%$ deles indicaram parentes próximos, em geral seus filhos para disputarem a cadeira na Câmara dos Deputados.

Pouco mais de um quinto desses congressistas apresentaram casos graves de corrupção, sendo essa a principal causa para o fim ou a pausa em eleições. 44\% desistiram sem ter um motivo claro aparente. A maioria estava respondendo processos, mas não há como afirmar que desistiram por causa da corrupção.

Três deputados faleceram, outros dois se aposentaram. Outro posto comumente ocupado por deputados é o cargo de Conselheiro nos Tribunais de Contas da União e dos Estados. Entre 2010 e 2014 foram quatro deputados federais.

Alguns políticos saem do Congresso Nacional e buscam diferentes postos, como o de Governador e de Senador. A Tabela 11 apresenta os índices de concentração para a média dos Deputados Federais que não disputaram a reeleição. É notória a necessidade de ser o mais desconcentrado possível para angariar postos eletivos de maior expressão, como Senador e Governador. Enquanto a média total está em 0,101, para o Governo é de 0,043 e para o Senado, 0,049 . 
Tabela 11 - Deputados Federais que buscaram outros postos

\begin{tabular}{c|c|c|c|c}
\hline Variável & TOTAL & GOVERNADOR & SENADOR & $\begin{array}{c}\text { DEPUTADO } \\
\text { ESTADUAL }\end{array}$ \\
\hline $\begin{array}{c}\text { Qtde. } \\
\text { Dep. }\end{array}$ & 158 & 8 & 19 & 13 \\
\hline Índice G & 0,101 & 0,043 & 0,049 & 0,085 \\
\hline
\end{tabular}

Fonte: Elaborado pelo autor, a partir de dados do TSE.

A maior parte dos Deputados Federais que deixaram de concorrer à reeleição o fez pelo envolvimento em processos relacionados à corrupção. Isso corrobora a hipótese inicial, de que a corrupção seria a causa principal do abandono da carreira eletiva. Além disso, aqueles que desistiram de concorrer a um novo mandato sem possuírem motivos evidentes tinham em sua maioria processos a responder na justiça.

\section{Conclusão}

Pela pesquisa bibliográfica é possível notar a falta de estudos relacionados à desistência ou às falhas de postulantes à reeleição na Câmara dos Deputados. Esses trabalhos tendem a buscar causas relacionadas à reeleição e não ao seu fracasso. A motivação deste trabalho surgiu dessa lacuna na literatura e, apesar das conclusões descobertas, ainda há um enorme campo de pesquisa nessa área.

Não são muitos os deputados que sofrem quedas significativas em suas votações de uma eleição para outra, isso indica que uma vez conquistada uma cadeira na Câmara, é difícil não permanecer nela após a próxima eleição. A não ser que o parlamentar em questão seja um novato na casa, já que foi mostrada a fragilidade eleitoral desse perfil político.

É importante salientar que cada Estado possui uma característica diferente e algumas variáveis de concentração não podem ser generalizadas para todos os distritos eleitorais. A hipótese inicial de que uma maior desconcentração eleitoral prejudicaria os candidatos à reeleição foi satisfeita 
nos Estados da Federação que possuem maior número de cadeiras na Câmara Federal. Nesses Distritos, se concentrar eleitoralmente é melhor do que se desconcentrar.

Para os Estados com menor representatividade o efeito é contrário, aqueles que buscam se concentrar eleitoralmente apresentam, em média, resultados piores que na eleição anterior. Enquanto aqueles que buscam uma votação mais dispersa no território estadual mostram mais chances de alcançar a reeleição. Portanto, a estratégia varia de Estado para Estado, tendo como principal fator de influência o número de cadeiras na Câmara Federal.

Os Deputados Federais envolvidos em escândalos de corrupção são responsáveis por grande parte daqueles que não concorreram à reeleição em 2014. Condição que satisfez a hipótese de que a corrupção teria grande influência para a não postulação. Outros parlamentares preferem disputar cargos no Executivo ou pleitear vaga no Senado.

Trabalhos futuros podem contribuir com uma avaliação da concentração eleitoral a partir de regiões pertencentes a cada Estado, isso captaria redutos eleitorais em municípios próximos, melhorando a qualidade da análise. Além disso, a busca por características intrínsecas a cada Estado deve ser feita para melhor entendimento da lógica eleitoral, pois o número de cadeiras na Câmara se mostrou uma variável muito significativa, mas outras características podem se mostrar também, relevantes para a tentativa de reeleição. 


\section{Bibliografia}

AMES, B. (1995). "Electoral strategy under open-list proportional representation". Em American Journal of Political Science, 406-433.

Biderman, C; Avelino, G; Peres da Silva, G; (2011). A Concentração Eleitoral nas Eleições Paulistas: Medidas e Aplicações. Dados - Revista de Ciências Sociais, 54(2) 319-347.

BERTHOLINI, F., FAJARDO, B. G., DE FAVERI, D., \& PEREIRA, C. (2013). "Does Legislative Work Help Reelection? Ambition, Reelection and Legislative Performance at the Subnational Level in Brazil." Em American Political Science Association 2013 Annual Meeting.

BOTERO, F., \& RENNÓ, L. R. (2007). "Career choice and legislative reelection: evidence from Brazil and Colombia." Brazilian Political Science Review (Online), 1 (SE), $0-0$.

BRASIL. Lei no 4.737, de 15 de julho de 1965. Institui o Código Eleitoral. Disponível em: <http://www.planalto.gov.br/ccivil_03/leis/L4737.htm>. Acesso em: 15 mai. 2016.

DE MAGALHÃES, L., \& HIRVONEN, S. (2015). "Multi-Office Incumbency Advantage: Political Careers in Brazil", (No. 15/662). Department of Economics, University of Bristol, UK.

DIERMEIER, D., KEANE, M., and MERLO, A. (2005). "A Political Economy Model of Congressional Careers." American Economic Review, 95(1): 347-373.

FIRPO, S., PONCZEK, V., \& SANFELICE, V. (2015). "The relationship between federal budget amendments and local electoral power". Journal of Development Economics, 116, 186-198.

FRIEDMAN, J. N., \& HOLDEN, R. T. (2009). "The Rising Incumbent Reelection Rate: What's Gerrymandering Got to Do With It?". The Journal of Politics, 71(02), 593-611.

GELMAN, A., \& KING, G. (1990). "Estimating incumbency advantage without bias." American Journal of Political Science, 1142-1164.

GOLDEN, M., \& PICCI, L. (2011). "Redistribution and reelection under proportional representation: the postwar italian chamber of deputies." MPRA Paper, (29956).

LEONI, E., PEREIRA, C., \& RENNO, L. (2004). "Political survival strategies: Political career decisions in the Brazilian Chamber of Deputies". Journal of Latin American Studies, 36(01), 109-130.

MAZZOCCO, M., \& FINAN, F. (2014). "Mis-allocation of Political Capital". Em 2014 Meeting Papers (No. 440). Society for Economic Dynamics. 
MESQUITA, L. (2008). "Emendas ao orçamento e conexão eleitoral na Câmara dos Deputados Brasileira." Originalmente apresentada como dissertação de mestrado. Universidade de São Paulo.

NICOLAU, J. (2006). "O Sistema Eleitoral de Lista Aberta no Brasil”.

Nils-Christian Bormann \& Matt Golder. (2013). "Democratic electoral Systems Around the World, 1946-2011." Electoral Studies 32: 360-369.

NUNES, F. (2010). "The Conditional Effect of Pork: The Strategic Use of Budget Allocation to Build Government Coalitions in Brazil" (Tese de Doutorado, Political Science Department-UCLA).

PEREIRA, C., \& MELO, M. A. (2016)."Reelecting Corrupt Incumbents in Exchange for Public Goods: 'Rouba Mas Faz in Brazil'.' Latin American Research Review-LARR, 51(1).

PEREIRA, C., \& RENNÓ, L. (2003). "Successful re-election strategies in Brazil: The electoral impact of distinct institutional incentives." Electoral Studies, 22(3), 425-448.

PEREIRA, C., \& RENNÓ, L. (2007). O que é que o reeleito tem? O retorno: o esboço de uma teoria da reeleição no Brasil. Revista de Economia Política, 27(4), 664-683.

PEREIRA, C., \& RENNÓ, L. (2013). 'Should I Stay or Should I Go?'Explaining Political Ambition by Electoral Success in Brazil. Journal of Politics in Latin America, 3, 73.

SAMUELS, D. (2000). "Ambition and competition: Explaining legislative turnover in Brazil." Legislative Studies Quarterly, 481-497.

SAMUELS, D. J. (2002). "Pork barreling is not credit claiming or advertising: Campaign finance and the sources of the personal vote in Brazil." The journal of Politics, 64(03), 845-863.

SCHMITT, R. (1999). Migração partidária e reeleição na Câmara dos Deputados. Novos Estudos Cebrap, 54(1), 127-146. 